\title{
Human Neutrophil Gelatinase Is a Component of Specific Granules
}

\author{
Margaret S. Hibbs*‡ and Dorothy F. Bainton $\$$ \\ *Division of Rheumatic Diseases, University of Connecticut Health Center and Veterans Administration Medical Center, Newington, \\ Connecticut 06111; ${ }^{\ddagger}$ University of Tennessee at Memphis and the Veterans Administration Medical Center, Memphis, Tennessee \\ 38104; and ${ }^{\S}$ Department of Pathology, University of California at San Francisco, San Francisco, California 94143
}

\begin{abstract}
Previous investigators have proposed that gelatinase, a metalloproteinase found in neutrophils, is stored in a novel secretory compartment distinct from the two major granule populations, azurophilic and specific. To locate this proteinase in human neutrophils we reacted the cells for peroxidase and then applied monospecific polyclonal antibodies to human neutrophil gelatinase to immunolabel ultrathin frozen sections using an immunogold technique. Gelatinase was localized in a population of peroxidase-negative granules. Double-labeling experiments using antibodies against lactoferrin, a marker for specific granules, and gelatinase demonstrated colocalization of the two antigens in $80 \%$ of the specific granules. However, some granules immunostained with only the lactoferrin or gelatinase antibody. Similar techniques were used to examine precursor cells from bone marrow. In myelocytes both gelatinase and lactoferrin were present in large developing specific granules; however, some mature specific granules contained only lactoferrin. Thus, it is possible that lactoferrin synthesis begins earlier than gelatinase synthesis and that overlapping synthesis and segregation occurs during the myelocyte stage. These findings suggest that the main storage compartment of gelatinase is within the peroxidase-negative specific granules.
\end{abstract}

\section{Introduction}

Most cells that express collagenolytic metalloproteinases actively synthesize and secrete these enzymes in response to specific stimuli. In this regard the neutrophil is a unique cell, differentiating within the bone marrow and synthesizing and storing secretory proteins in separate granule compartments destined for later release (1). During this maturation phase the neutrophil compartmentalizes three proteinases that may be important in the degradation of the collagenous components of the extracellular matrix. These proteinases include elastase, a serine proteinase stored in the primary or azurophil granule (2); collagenase, a metalloproteinase stored in the secondary or specific granule (3); and gelatinase, a metalloproteinase that has been proposed as a marker of a third granule compartment, the $C$ particle compartment (4).

Although each of these proteinases has different substrate specificities and unique secretion characteristics (5), attention

A preliminary report of this work was published in abstract form (1986. Clin. Res. 34:459A).

Address correspondence to Dr. Margaret S. Hibbs, Research Service (151), Veterans Administration Medical Center, Building 5, 555 Willard Avenue, Newington, CT 06111.

Received for publication 29 February 1989 and in revised form 27 April 1989.

The Journal of Clinical Investigation, Inc.

Volume 84, November 1989, 1395-1402 has focused on the tentative localization of gelatinase to a novel secretory compartment. The existence of this unique compartment has been suggested by the studies of Dewald et al. (4), which demonstrated that gelatinase was detectable in the extracellular milieu in response to stimuli that were incapable of inducing significant release of $B_{12}$ binding protein, a component of specific granules. Thus, the concept of a separate storage compartment whose contents are destined for secretion into the extracellular environment has been proposed (4). As this compartment has been defined solely on the basis of subcellular fractionation $(4,6)$ and functional studies (4-6) it was of interest to define this compartment morphologically.

We previously reported the purification of human neutrophil gelatinase and the preparation of monospecific polyclonal antibodies to this proteinase (7). We have used these antibodies to immunolocalize neutrophil gelatinase. Our results suggest that factors other than simple compartmentalization may be important in understanding the different secretion characteristics among various granule proteins.

\section{Methods}

Preparation of neutrophils. Human blood leukocytes were isolated by dextran sedimentation (8). After washing with PBS and centrifugation at low speed to remove the contaminating platelets (9) leukocytes were immediately fixed for electron microscopy. Bone marrow was obtained from the ribs of hematologically normal patients undergoing cardiothoracic surgery.

Antibodies. Gelatinase antibodies were prepared by immunization of either the $92-\mathrm{kD}$ form of neutrophil gelatinase isolated by preparative gel electrophoresis (7) or the native purified proteinase. Both antibodies demonstrated identical immunostaining patterns and neither antibody was found to react with neutrophil collagenase in immunoblotting or immunoprecipitation experiments. Purified IgG was obtained by affinity chromatography on protein A-Sepharose (10).

To further assure the specificity of the antibody the gelatinase antiserum was affinity purified using the technique of Olmstead (11). In brief, the purified antigen was electrophoresed on an $8 \%$ polyacrylamide gel and transferred to nitrocellulose by Western blotting. The area corresponding to the $92-\mathrm{kD}$ form of gelatinase was identified by aligning strips cut from the original nitrocellulose on which the proteinase had been immunologically demonstrated. This area was cut into 1-mm squares and used as a solid-phase absorbent to affinity purify the antibody. After blocking any additional protein binding sites by incubation with $3 \%$ BSA the squares were incubated with the antiserum for $1 \mathrm{~h}$ at room temperature and overnight at $4^{\circ} \mathrm{C}$. The squares were then washed extensively with $20 \mathrm{mM}$ Tris- $\mathrm{HCl}, \mathrm{pH} 7.5$, containing $0.15 \mathrm{M} \mathrm{NaCl}, 0.05 \%$ Tween-20, and $0.1 \% \mathrm{BSA}$. The bound antibody was eluted with $0.2 \mathrm{M}$ glycine- $\mathrm{HCl}$ and $0.2 \mathrm{M} \mathrm{NaCl}, \mathrm{pH} 2.8$. The eluted material was neutralized with $1.0 \mathrm{~N} \mathrm{NaOH}$ and concentrated by chromatography on protein A-Sepharose.

The lactoferrin polyclonal antibody was obtained from Accurate Chemical \& Scientific Corp. (Westbury, NY).

Gel electrophoresis and immunoblotting. SDS-PAGE was performed by the method of Laemmli (12). Western blotting and developing were performed as previously described (7) using a biotin-avidin 
amplification system to enhance sensitivity (Vectastain; Vector Laboratories, Inc., Burlingame, $\mathrm{CA}$ ).

Immunoprecipitation. PBL from patients with chronic myelogenous leukemia were isolated from buffy coat preparations, washed with PBS, cultured in methionine-free Dulbecco's MEM in the presence of $50 \mu \mathrm{Ci} / \mathrm{ml}\left[{ }^{35} \mathrm{~S}\right]$ methionine for $4 \mathrm{~h}$, and then incubated with either buffer, $10 \mathrm{ng} / \mathrm{ml}$ phorbol myristic acetate (PMA) $)^{1}$ or $10^{-7} \mathrm{M}$ FMLP for $15 \mathrm{~min}$. Culture supernatants and cell lysates were prepared and analyzed as previously described (5). We have previously demonstrated that monocytes/lymphocytes secrete no gelatinolytic proteinases under these conditions (7). Gelatinase was immunoprecipitated from culture supernatants and NP-40 $(0.1 \% \mathrm{wt} / \mathrm{vol})$ cell lysates as previously described (13).

Electron microscopy. The cells were fixed in $2 \%$ paraformaldehyde-0.05\% glutaraldehyde in $0.1 \mathrm{M}$ PBS, pH 7.4, for $1 \mathrm{~h}$ at $22^{\circ} \mathrm{C}$. They were washed in phosphate buffer, in some cases incubated for peroxidase (14), and processed for frozen thin sections. In brief, after washing the fixed cells in $0.1 \mathrm{M}$ phosphate buffer containing $5 \%$ (wt/ vol) sucrose the cells were then infused with $2.1 \mathrm{M}$ sucrose in PBS for $30 \mathrm{~min}$, embedded in the same solution, and frozen and stored in liquid nitrogen. The frozen thin sections were prepared using a Reichert Ultracut E microtome (Cambridge Instruments, Inc., Ossining, NY). The techniques described by Tokuyasu (15) with the modifications described by Griffiths et al. (16) were then used. The primary antibody for gelatinase was used at a dilution of 1:250-1:500, or the lactoferrin antibody was used at a dilution of 1:500. Immunogold probes, goat anti-rabbit-5, protein A-5, and protein A-10 (Janssen Pharmaceutica, Beerse, Belgium) were used at dilutions of 1:50 and $1: 20$, respectively. Gelatinase antibody preparations include antibodies isolated against material isolated on preparative gels, the native purified antigen, and affinity-purified antigen. Controls included the use of preimmune IgG or nonimmune rabbit antisera or buffer in place of the immune Ig. Double-labeling experiments to colocalize gelatinase and lactoferrin were performed using protein $\mathrm{A}$ as described by Slot and Geuze (17). The antibody against gelatinase was applied and labeled with protein A-5. Before the secondary antibody was applied free protein $\mathrm{A}(0.05 \mathrm{mg} / \mathrm{ml})$ was applied. Subsequently, antibodies to lactoferrin were applied, followed by protein A-10. The grids were then stained with uranyl acetate and embedded in methylcellulose.

\section{Results}

In previous studies we reported the purification of neutrophil gelatinase (7). The enzyme purified to a high specific activity was found to consist of three polypeptides $\left(M_{\mathrm{r}}=225,000\right.$, 130,000 , and 92,000) under nonreducing conditions and a single protein $\left(M_{\mathrm{r}}=92,000\right)$ upon reduction. All species were immunologically crossreactive and demonstrated identical substrate specificities. The purified protein was used to develop monospecific polyclonal antibodies to this proteinase.

Fig. $1 A$ demonstrates the specificity of the antibodies against gelatinase (panel $a$ ) when tested by Western blotting against either Triton X-100 extracts of unstimulated neutrophils $\left(5 \times 10^{5}\right)$ (lane 1$)$ or the secretory products of cells after stimulation with PMA for $15 \mathrm{~min}$ at $37^{\circ} \mathrm{C}$ (lane 2). Only the three secretory forms of gelatinase previously demonstrated are seen (7). The reaction pattern was identical whether the antibody used was obtained by immunization with the antigen obtained by preparative electrophoresis, by immunization with the native proteinase, or by antibodies against the native antigen that were affinity purified or crossabsorbed with neutrophil collagenase.

1. Abbreviations used in this paper: PMA, phorbol 12-myristic 13-acetate.
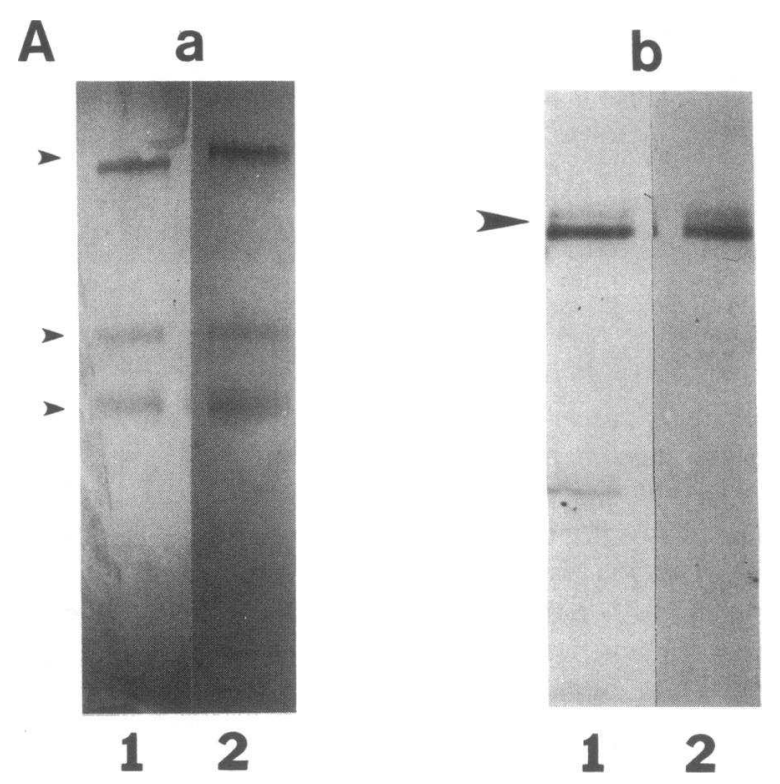

B
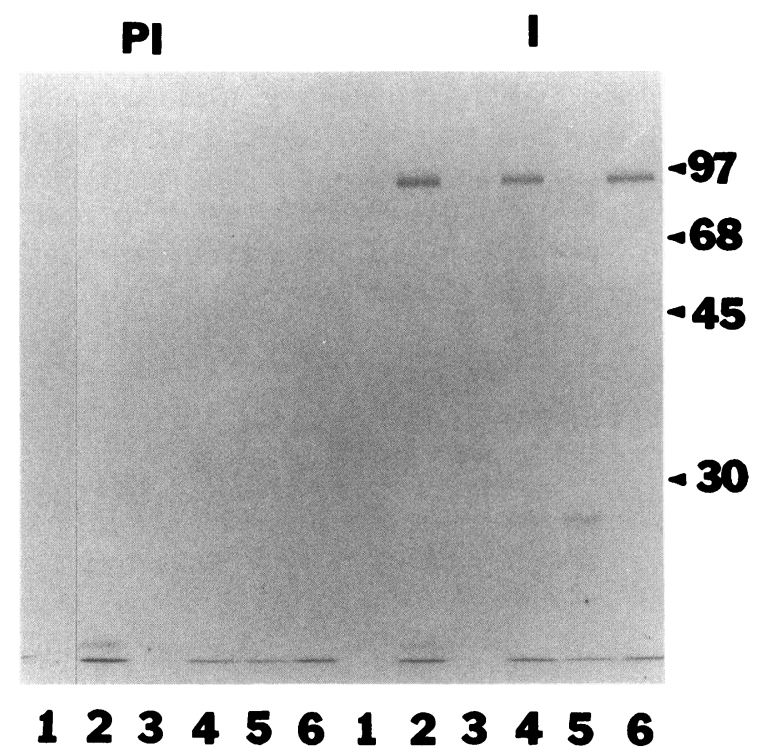

Figure 1. $A$, Immunoblots showing the reactivity of gelatinase and lactoferrin antibodies. Neutrophils $\left(5 \times 10^{5}\right)$ were treated with $0.1 \%$ Triton X-100 (lanes 1 ) or stimulated with $20 \mathrm{ng} / \mathrm{ml}$ PMA for $15 \mathrm{~min}$ (lanes 2). The cell extract and culture supernatant were analyzed for immunoreactivity with antibodies against gelatinase $(a)$ or against lactoferrin $(b)$. Antibody dilutions were 1:100 for the gelatinase antibody and 1:400 for the lactoferrin antibody. The small arrowheads in $a$ indicate the secreted forms of neutrophil gelatinase. The arrowhead in $b$ indicates lactoferrin. $B$, Immunoprecipitates from ${ }^{35} \mathrm{~S}$-labeled proteins from neutrophil precursors. Neutrophils/neutrophil precursers were cultured for $4 \mathrm{~h}$ in the presence of $\left[{ }^{35} \mathrm{~S}\right]$ methionine at $37^{\circ} \mathrm{C}$ and then stimulated with either buffer, PMA, or FMLP for 15 min at $37^{\circ} \mathrm{C}$. Culture supernatants (lanes $1-3$ ) and cell lysates (lanes 4-6) were immunoprecipitated using $10 \mu \mathrm{g}$ of either preimmune IgG $(P I)$ or antigelatinase IgG $(I)$.

The specificity of the gelatinase antibodies was further indicated by immunoprecipitation studies of $\left[{ }^{35} \mathrm{~S}\right]$ methioninelabeled neutrophil precursors. Neutrophils/neutrophil precursors isolated from the peripheral blood of patients with chronic myelogenous leukemia were incubated for $4 \mathrm{~h}$ with $50 \mu \mathrm{Ci} / \mathrm{ml}$ 
$\left[{ }^{35} \mathrm{~S}\right]$ methionine and then stimulated for $15 \mathrm{~min}$ with either buffer, PMA (50 ng/ml), or FMLP $\left(10^{-7} \mathrm{M}\right)$. Immunoprecipitates of the culture supernatants and cell pellet extracts are shown in Fig. $1 B$. In the unstimulated and FMLP-stimulated cells, 92-kD gelatinase was prominently detected in the cell extracts (panel $I$, lanes 4 and 6). In contrast, in the sample stimulated with PMA the majority of the immune reactivity is found in the culture supernatant (panel $I$, lane 2). Most of the activity remaining in the cell extract is present as a $30-\mathrm{kD}$ degradation fragment. Thus, the antibody preparation appears specific in both immunoblotting and immunoprecipitation studies.

The lactoferrin antibody reacted intensely with a protein of $79 \mathrm{kD}$. As lactoferrin is a glycosylated protein, some heterogeneity in molecular forms may be evident. Nonimmune rabbit IgG gave no staining. Our immunolocalization results obtained using this lactoferrin antibody were identical to those obtained previously by other investigators $(18,19)$.

Fig. 2 demonstrates the immunogold staining on a frozen thin section of a neutrophil after incubation with the gelatinase antibody. Small gold particles are noted in a major granule population that morphologically resembles specific granules. The azurophil granules were partially solubilized so that they appear electronlucent in areas. Such solubilization was noted in other studies using this technique (20). Despite this phenomenon it is important to note that no antigen is detected in the azurophil granule population. The studies of Ganz et al. (20) showed that despite partial solubilization of the granule contents antigens localized there remained detectable.
To clearly identify the azurophil granules, the neutrophils were reacted with 3,3-diaminobenzidine in the presence of $\mathrm{H}_{2} \mathrm{O}_{2}$. Under these conditions the azurophil granule contents were well preserved and appeared dense (Fig. 3). When such sections were incubated with gelatinase antibody followed by immunogold labeling, the antigen localized in a major peroxidase-negative specific granule compartment; $\sim 90 \%$ of the peroxidase-negative specific granules labeled with gold. No staining was seen when normal rabbit antisera or preimmune IgG was used instead of the anti-gelatinase IgG. The identical localization was obtained when affinity-purified antibody was used, although fewer gold particles were seen.

While these results suggest that gelatinase was localized in the specific granule compartment, studies were undertaken to colocalize it with a known marker of this compartment, lactoferrin. A previous study (21) showed that lactoferrin was present in $80-90 \%$ of the peroxidase-negative specific granules. In this study the sections were first reacted with the gelatinase antibody followed by protein A-gold-5, and then incubated with the lactoferrin antibody followed by protein A-gold-10. If the lactoferrin antibody was omitted or nonimmune serum was substituted, no staining with the larger protein A-gold particles was noted. As seen in Fig. 4, both the large and small gold particles localized to $\sim 80 \%$ of the specific granules, indicating colocalization of lactoferrin and gelatinase. Although the majority of the granules contained both antigens, there were some granules that only stained with one size of gold particle. More precisely, counts were made on 305 peroxidase-negative specific granules and colocalization of small and

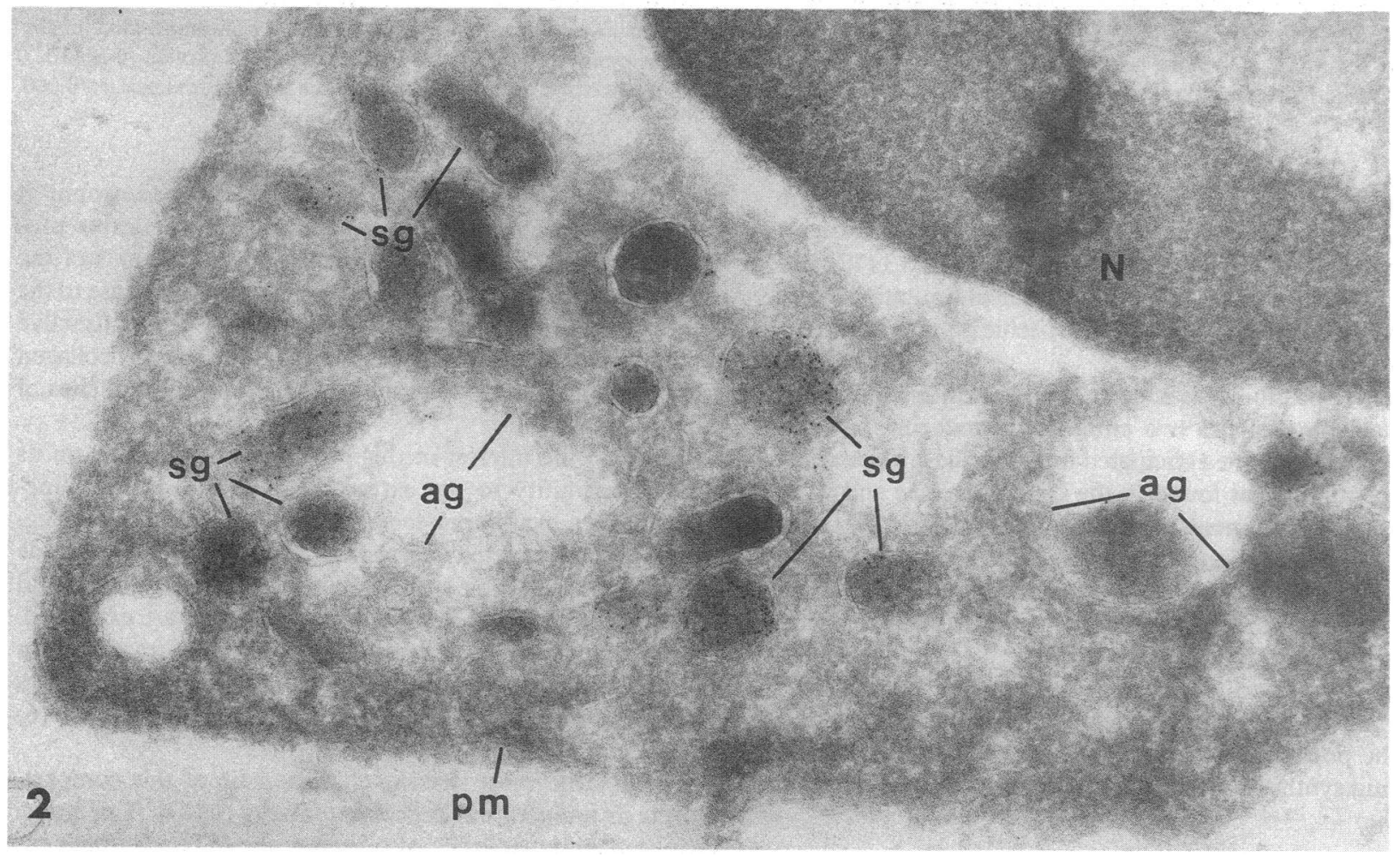

Figure 2. Neutrophil gelatinase localization in a portion of cytoplasm from a human neutrophilic leukocyte, fixed, frozen thin-sectioned, incubated with antibody to gelatinase, and immunolabeled with goat anti-rabbit-5. The presence of gelatinase is denoted by the numerous gold particles present in many specific granules $(s g)$. Note that the large, partially extracted azurophilic granules $(a g)$ do not contain the antigen, as is the case in some of the specific granules. $N$, nucleus; $p m$, plasma membrane. $\times 58,000$. 


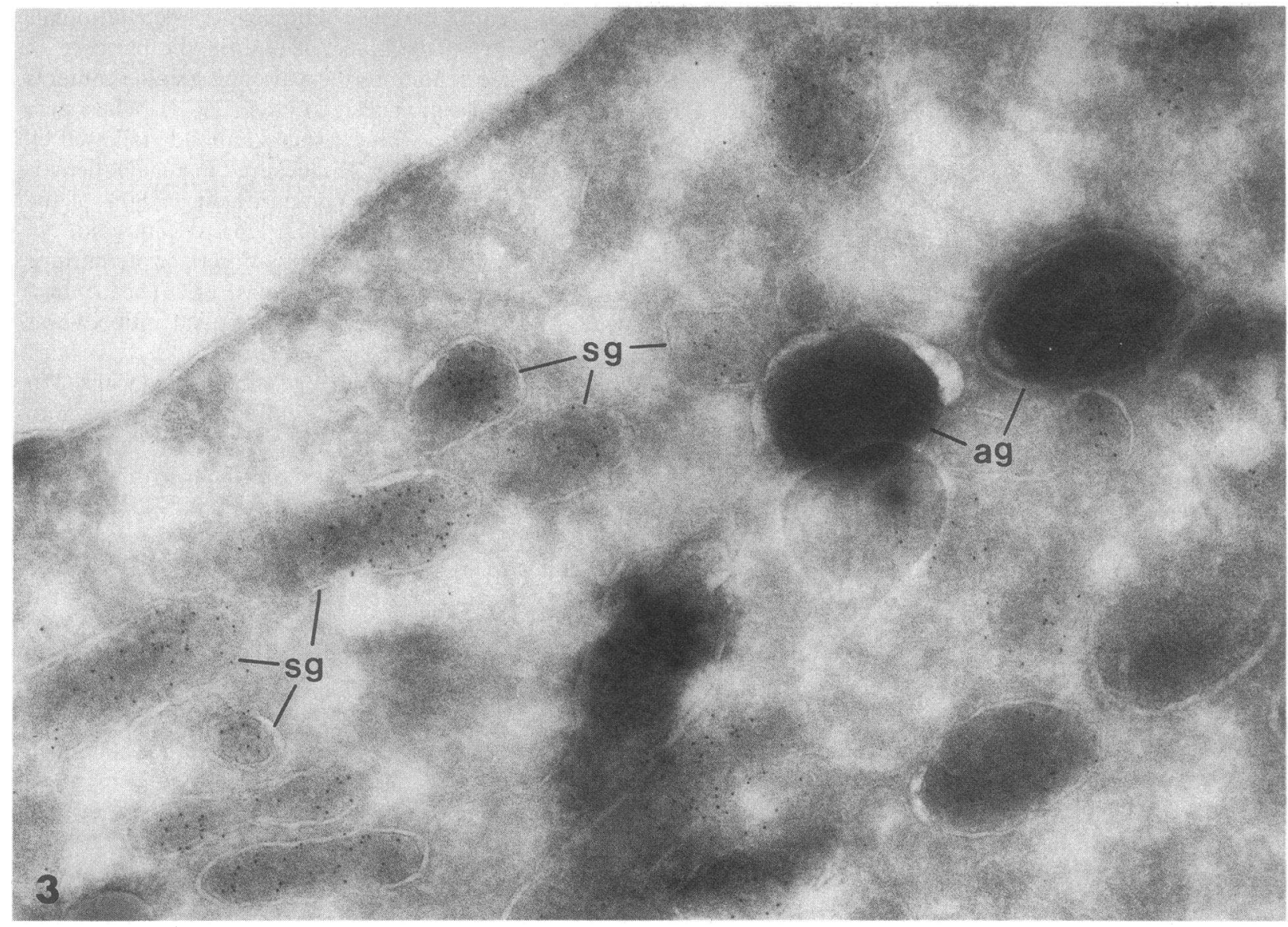

Figure 3. Gelatinase localization in neutrophils that were reacted to reveal the presence of endogenous peroxidase. The cells were fixed, reacted with 3,3-diaminobenzidine and $\mathrm{H}_{2} \mathrm{O}_{2}$ to reveal endogenous peroxidase, infused with sucrose, frozen thin-sectioned, and immunoreacted for the presence of gelatinase. As before, gelatinase is present in many peroxidase-negative granules $(\mathrm{sg})$ as noted by the presence of protein A-gold 5 . The contents of dense azurophil granules (ag) are now well preserved because of the reaction product of endogenous myeloperoxidase. $\times 70,000$

large gold was seen in $256(84 \%)$. In the remainder of the specific granules counted, $22(7 \%)$ stained with gelatinase alone, $14(5 \%)$ stained with lactoferrin alone, and $13(4 \%)$ did not stain. Whether this is related to technical limitations or is an indication of heterogeneity in the specific granule compartment is unclear.

The latter possibility is suggested by the differential compartmentalization of the two antigens in maturing myeloid precursors. As would be anticipated for a specific granule component, gelatinase was found in the Golgi cisternae and adjacent Golgi vesicles of neutrophilic myelocytes (Fig. $5 \mathrm{~b}$ ). Interestingly, lactoferrin alone was noted in the mature specific granules, while both gelatinase and lactoferrin were found in the larger, immature specific granules (Fig. 5 a). In more mature neutrophils from the same specimen (Fig. $5 c$ ) colocalization of gelatinase and lactoferrin in the specific granules appeared similar to that seen in peripheral blood. These findings suggest the possibility that there may be sequential, partially overlapping synthesis of some of the components of specific granules.

\section{Discussion}

Gelatinase is an important member of the proteinase system that is involved in degradation of the collagenous components of the extracellular matrix. In the context of the neutrophil it acts together with neutrophil collagenase and the serine proteinase, elastase, to degrade all the major components of the extracellular matrix. The rapid accessibility of gelatinase to the extracellular environment suggests that it may be an attractive candidate for a role in the degradation of type IV collagen during the physiologic migration of the neutrophil to sites of inflammation (22).

Much of the interest in this proteinase has focused on its rapid accessibility to the extracellular environment. Functional studies examining the release of gelatinase have suggested that it is secreted in response to stimuli such as fluoride (23) and FMLP $(4,6)$ under conditions where minimal amounts of traditional specific granule markers are expressed. These studies have been reinforced by granule fractionation studies that have suggested that gelatinase is stored in a less dense granule compartment than the specific granule $(6$, 23, 24).

Perhaps the most striking characteristic of this compartment is its temperature-dependent lability $(4,23)$. This translocation phenomenon has also been reported for complement receptor type I (25), complement receptor type $3(25,26)$, decay accelerating factor (27), and alkaline phosphatase (24). Interestingly, subcellular fractionation studies suggest that these proteins are stored in different compartments ranging 


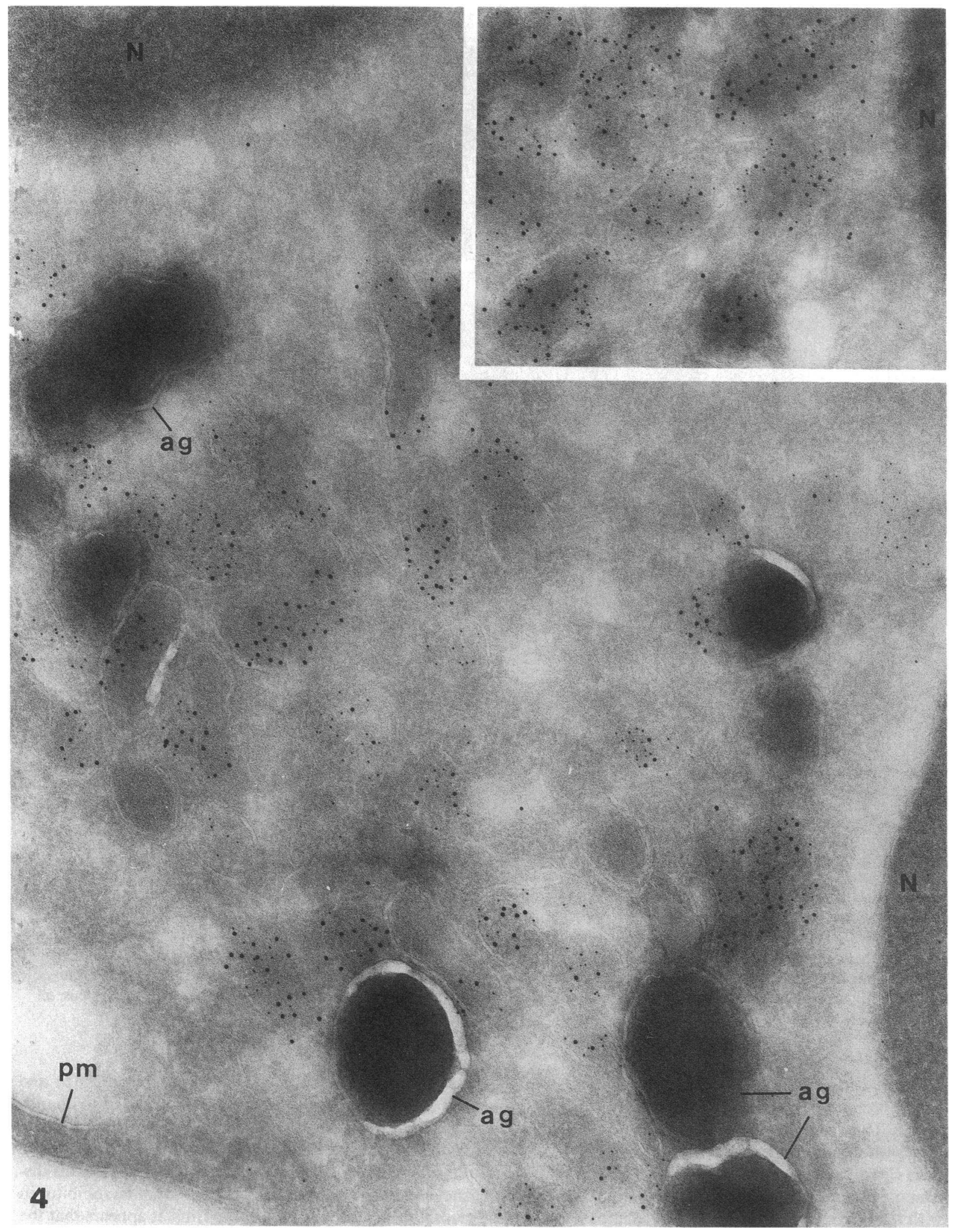

Figure 4. Colocalization of gelatinase and lactoferrin. Shown is a portion of a neutrophil that was incubated for peroxidase to mark the large, dense azurophil granules $(\mathrm{ag})$ and then double-labeled with antibodies against gelatinase and lactoferrin. The smaller gold particles (dots of 5 $\mathrm{nm}$ ) denote the presence of gelatinase and the larger gold particles the presence of lactoferrin. Note that $\sim 80 \%$ of the peroxidase-negative granules contain gold particles of both sizes. (Inset) Similar field showing colocalization of small and large gold particles. $N$, Nucleus; $p m$, plasma membrane. $\times 76,000$. 


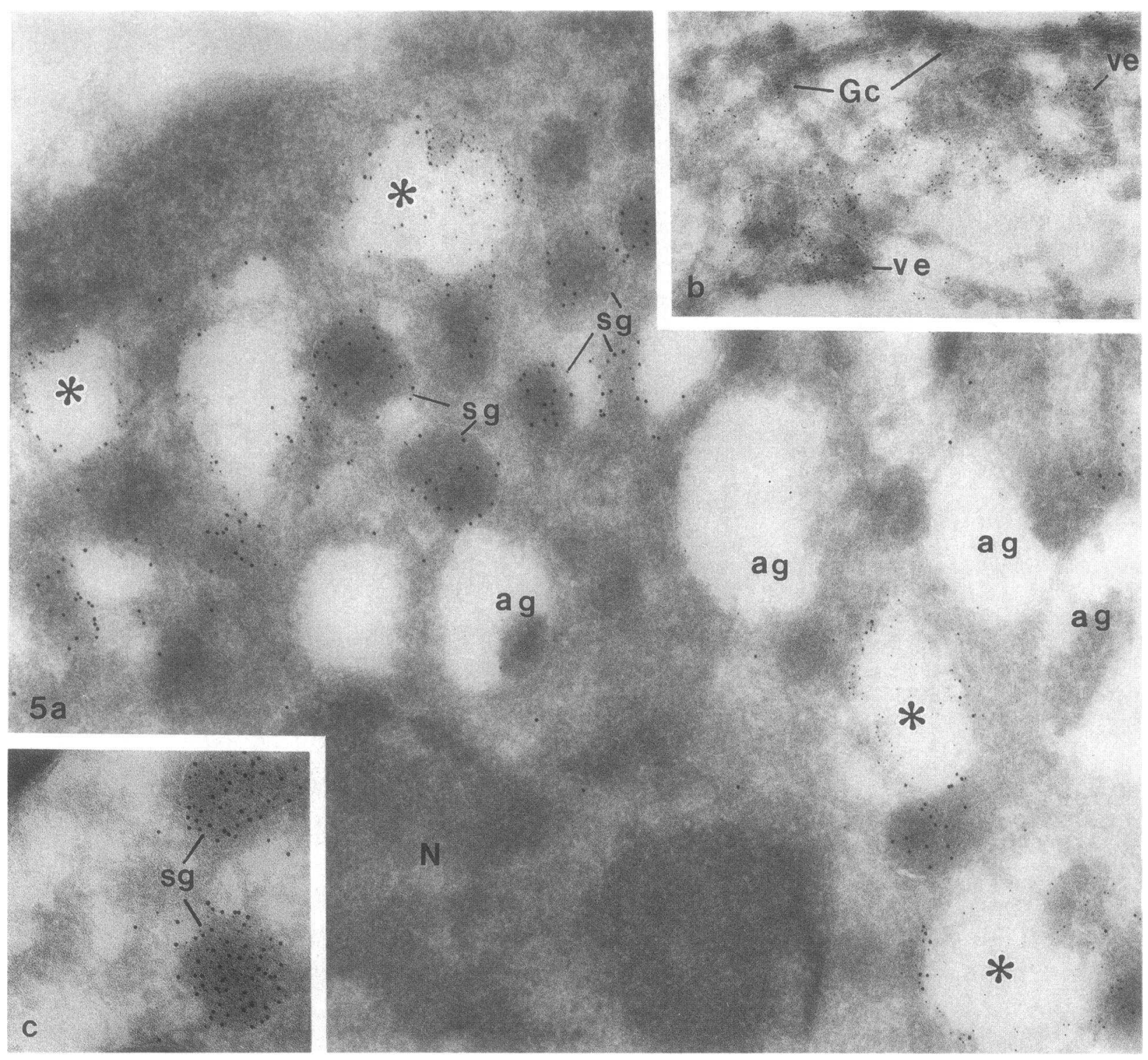

Figure 5. a, Localization of gelatinase (smaller gold particles) and lactoferrin (larger gold particles) in a portion of a neutrophilic myelocyte from human bone marrow. Azurophil granules ( $a g$ ), which appear partially extracted, were formed during the earlier promyelocyte stage (1). Some specific granules $(\mathrm{sg}$ ) containing only lactoferrin (larger gold particles) have already been formed. Note also the presence of large, immature specific granules that contain both sizes of gold particles, indicating the presence of both lactoferrin and gelatinase within the same organelle (*). $b$, Golgi complex of a myelocyte incubated for gelatinase alone. Note the presence of gold in the Golgi cisternae (Gc) and adjacent Golgi vesicles (ve). $c$, Appearance of double label in specific granules of a more mature neutrophil from the same preparation. $N$, Nucleus. $a$, $\times 48,000 ; b, \times 48,000 ; c, \times 60,000$.

from a compartment similar in density to the plasma membrane (alkaline phosphatase) to the specific granule (complement receptor 3 ). Thus, secretory characteristics do not necessarily correlate with the storage location.

Our studies clearly indicate that gelatinase is a component of a major granule peroxidase negative compartment. Its colocalization with lactoferrin clearly suggests that gelatinase is a component of the morphologically defined specific granule compartment. While a lack of staining does not exclude the possibility that some gelatinase may be stored in other compartments, it does appear that the major storage compartment for this enzyme is the specific granule.

One potential explanation for the discrepancy may be re- lated to the functional assay. Our previous studies (5) and those of others $(6,23)$ have found that it is difficult to quantitate gelatinase secretion in terms of \% release. Extracts of unstimulated cells consistently demonstrate less activity than the culture supernatants of maximally stimulated cells. This discrepancy has been attributed to the presence of an inhibitor in the cytosol of neutrophils $(5,6,28)$. Thus, it appears that the quantitation of $\%$ release based on functional determinations could lead to an overestimation of rate of secretion.

An additional complication in the functional determinations may be related to the effects of concomitant hydroxyradical secretion by activated neutrophils. The conventionally used marker of specific granule compartment degranulation is 
$\mathrm{B}_{12}$ binding protein. The assay of this marker is dependent on a functional assay which may be inaccurate in the presence of oxidized reagents (29). Concomitantly, gelatinase may be activated and detected more readily after exposure to oxidants (30). Thus, $B_{12}$ binding protein secretion may be underestimated while gelatinase secretion is overestimated.

Despite the apparent discrepancies using functional assays, studies using antibody probes for the detection of granule constituents have correlated with localization data. The complement receptor type 3 which is identical to the leukocyte adhesion receptor designated Macl or Mol is translocated to the neutrophil cell surface in parallel with gelatinase secretion (23). This molecule has been shown to be an integral membrane protein of the specific granule by cell fractionation studies $(25,31)$ and has been localized to the specific granule membrane in ultrastructural studies (21). Thus, our studies indicating a primary localization of gelatinase to the specific granule compartment are consistent with the functional, cell fractionation, and localization studies of leukocyte adhesion proteins.

It is possible that there is a continuum of packaging of granule constituents during the myeloid development. A similar phenomenon has been reported in pancreatic secretory granules (32). For example, lactoferrin could be synthesized during the early- and mid-myelocyte stages, whereas gelatinase could be produced in the mid- to late myelocyte stages. This possibility is suggested by the lack of total colocalization of gelatinase and lactoferrin and by the differences in the contents of mature and developing granules at the myelocytic stage of differentiation. The latter findings suggest that the contents of specific granules may be determined by the actual proteins being synthesized at the time of granule formation. This hypothesis is reinforced by the recent studies of Fouret et al. (33) which demonstrated sequential overlapping transcription of myeloperoxidase, elastase, and lactoferrin genes. Thus, it is conceivable that there may be microheterogeneity within the morphologically defined specific granule compartment.

While there are apparent differences between the localization data and the functional studies, it is clear that gelatinase localizes primarily in a peroxidase-negative granule compartment that morphologically resembles the specific granule. A separate tertiary granule compartment was not identified. However, another compartment has been recently identified by labeling with human lysosomal membrane glycoproteins. This novel compartment is composed of small and large vesicles and multivesicular bodies (34). Additional studies using immunologic and/or in situ hybridization methods of developing neutrophils in conjunction with more traditional functional studies should enhance our understanding of granule composition and heterogeneity.

\section{Acknowledgments}

We are grateful for the professional assistance of Ms. Yvonne Jacques and the helpful discussions with Dr. Zena Werb and Dr. Andrew H. Kang.

This work was supported by grants AR-01138 and DK-10486 from the National Institutes of Health (NIH) and funds from the Veterans Administration. During the course of this research Dr. Hibbs was the recipient of a Clinical Investigator Award from the NIH and is currently the recipient of a Research Associate Award from the Veterans Administration.

\section{References}

1. Bainton, D. F., J. L. Ullyot, and M. G. Farquar. 1971. Development of neutrophilic polymorphonuclear leukocytes in human bone marrow. J. Exp. Med. 134:907-934.

2. Bretz, U., and M. Baggiolini. 1974. Biochemical and morphological characterization of azurophil and specific granules of human neutrophilic polymorphonuclear leukocytes. J. Cell Biol. 63:251-269.

3. Murphy, G., J. J. Reynolds, U. Bretz, and M. Baggiolini. 1977. Collagenase is a component of the specific granules of human neutrophil leukocytes. Biochem. J. 162:195-197.

4. Dewald, B., U. Bretz, and M. Baggiolini. 1982. Release of gelatinase from a novel secretory compartment of human neutrophils. $J$. Clin. Invest. 70:518-525.

5. Hibbs, M. S., K. A. Hasty, A. H. Kang, and C. L. Mainardi. 1984. Secretion of collagenolytic enzymes by human polymorphonuclear leukocytes. Collagen Relat. Res. 4:467-477.

6. Murphy, G., U. Bretz, M. Baggiolini, and J. J. Reynolds. 1980. The latent collagenase and gelatinase of human polymorphonuclear leukocytes. Biochem. J. 192:517-525.

7. Hibbs, M. S., K. A. Hasty, A. H. Kang, and C. L. Mainardi. 1985. Biochemical and immunological characterization of the secreted forms of human neutrophil gelatinase. J. Biol. Chem. 260:2493-2500.

8. Boyum, A. 1968. Isolation of mononuclear cells and granulocytes from human blood. Scand. J. Clin. Lab. Invest. 21(Suppl 97):77-89.

9. Sanderson, R. J., F. T. Sheppardson, A. E. Vatter, and D. W. Talmage. 1977. Isolation and enumeration of peripheral blood monocytes. J. Immunol. 118:1409-1414.

10. Ey, P. L., S. J. Prowse, and C. R. Jenkin. 1978. Isolation of pure IgG, IgG2alpha and IgG2b immunoglobulins from mouse serum using protein A sepharose. Immunochemistry. 15:429-436.

11. Olmstead, J. 1981. Affinity purification of antibodies from diazotised paper blots of heterogeneous protein samples. J. Biol. Chem. 256:11955-11957.

12. Laemmli, U. K. 1970. Cleavage of structural proteins during the assembly of the head of bacteriophage T4. Nature (Lond.). 227:680-685.

13. Hibbs, M. S., J. R. Hoidal, and A. H. Kang. 1987. Expression of a metalloproteinase which degrades native type $\mathrm{V}$ collagen and denatured collagens by cultured human alveolar macrophages. J. Clin. Invest. 80:1644-1650.

14. Graham, R. C., and M. Y. Karnovsky. 1966. The early stages of absorption of injected horseradish peroxidase in the proximal tubules of mouse kidney: ultrastructural cytochemistry by a new technique. $J$. Histochem. Cytochem. 14:291-302.

15. Tokuyasu, K. T. 1980. Immunochemistry on ultrathin frozen sections. Histochem. J. 12:381-403.

16. Griffiths, G., A. McDowall, R. Back, and J. Dubochet. 1984. On the preparation of cryosections for immunocytochemistry. J. Ultrastruct. Res. 89:65-78.

17. Slot, J. W., and H. J. Geuze. 1984. Gold markers for single and double immunolabelling of ultrathin cryosections. In Immunolabelling for Electron Microscopy. J. M. Polak and I. M. Varndell, editors. Elsevier, Oxford. 129-142.

18. Pryzwansky, K. B., L. E. Martin, J. K. Spitznagel, and J. C. Herion. 1978. Immunocytochemical localization of myeloperoxidase, lactoferrin, lysozyme and neutral proteases in human monocytes and neutrophilic granulocytes. J. Reticuloendothel. Soc. 24:295-310.

19. Cramer, E., K. B. Prywansky, J. Villeval, U. Testa, and J. Breton-Gorius. 1985. Ultrastructural localization of lactoferrin and myeloperoxidase in human neutrophils by immunogold. Blood. 65:423-432.

20. Ganz, T., M. E. Selsted, D. Szklarek, S. S. L. Harwig, K. Daher, D. F. Bainton, and R. I. Lehrer. 1985. Defensins. Natural peptide antibiotics of human neutrophils. J. Clin. Invest. 76:1427-1435.

21. Bainton, D. F., L. J. Miller, T. K. Kishimoto, and T. A. 
Springer. 1987. Leukocyte adhesion receptors are stored in peroxidase-negative granules in human neutrophils. J. Exp. Med. 166:16411653.

22. Murphy, G., J. J. Reynolds, U. Bretz, and M. Baggiolini. 1982. Partial purification of collagenase and gelatinase from human polymorphonuclear leukocytes. Biochem. J. 203:209-221.

23. Petrequin, P. R., R. F. Todd, L. J. Devall, L. A. Boxer, and J. T. Curnutte. 1987. Association between gelatinase release and increased plasma membrane expression of the Mol glycoprotein. Blood. 69:605-610.

24. Borregaard, N., L. J. Miller, and T. A. Springer. 1987. Chemoattractant regulated fusion of a novel, mobilizable intracellular compartment with the plasma membrane in human neutrophils. Science (Wash. DC). 237:1204-1206.

25. O’Shea, J. J., E. J. Brown, B. E. Seligmann, J. A. Metcalf, M. M. Frank, and J. I. Gallin. 1985. Evidence for distinct intracellular pools of receptors for $\mathrm{C} 3 \mathrm{~b}$ and $\mathrm{C} 3 \mathrm{bi}$ in human neutrophils. J. Immunol. 134:2580-2587.

26. Fearon, D. T., and L. A. Collins. 1983. Increased expression of $\mathrm{C} 3 \mathrm{~b}$ receptors on polymorphonuclear leukocytes induced by chemotactic factors and by purification procedures. J. Immunol. 130:370375.

27. Berger, M., and M. E. Medof. 1987. Increased expression of complement decay acceleration factor activation of human neutrophils. J. Clin. Invest. 79:214-220.
28. Lazarus, G. S., J. R. Daniels, R. S. Brown, H. A. Bladen, and H. M. Fullmer. 1968. Degradation of collagen by a human granulocyte collagenolytic system. J. Clin. Invest. 47:2622-2629.

29. Clark, R. A., and N. Borregaard. 1985. Neutrophils autoinactivate secretory products by myeloperoxidase catalyzed oxidation. Blood. 24:375-381.

30. Peppin, G. J., and S. J. Weiss. 1986. Activation of the endogenous metalloproteinase, gelatinase, by triggered human neutrophils. Proc. Natl. Acad. Sci. USA. 83:4322-4326.

31. Todd, R. F., A. Arnaout, R. E. Rosin, C. A. Crawley, W. A. Peters, and B. M. Babior. 1984. Subcellular localization of the large subunit of Mol (Molalpha, formerly gp 110) a surface glycoprotein associated with neutrophil adhesion. J. Clin. Invest. 74:1280-1290.

32. Mroz, E. A., and C. Lechene. 1986. Pancreatic zymogen granules differ markedly in protein composition. Science (Wash. DC). 232:871-873.

33. Fouret, P., R. M. DuBois, J. F. Bernaudin, H. Takahashi, V. J. Ferrans, and R. G. Crytsal. 1989. Expression of the neutrophil elastase gene during human bone marrow cell differentiation. J. Exp. Med. 169:833-845.

34. Bainton, D. F., and J. T. August. 1988. Multivesicular bodies of human neutrophils, not granules, immunolabel with the two major lysosmal membrane glycoproteins, hLAMP-1 and hLAMP-2. J. Histochem. Cytochem. 36:953. (Abstr.) 